\title{
An in vitro immune response model to determine tetanus toxoid antigen (vaccine) specific immunogenicity: Selection of sensitive assay criteria
}

\author{
Sytse J. Piersma ${ }^{\mathrm{a}, \mathrm{b}, \mathrm{c}}$, Marlies P.P.A.M. Leenaars ${ }^{\mathrm{b}, *}$, Laurence Guzylack-Piriou ${ }^{\mathrm{a}}$, \\ Artur Summerfield ${ }^{\mathrm{a}}$, Coenraad F.M. Hendriksen ${ }^{\mathrm{b}, \mathrm{c}}$, Ken C. McCullough ${ }^{\mathrm{a}}$ \\ a Institute of Virology and Immunoprophylaxis (IVI), Sensemattstrasse 293, CH-3147 Mittelhäusern, Switzerland \\ ${ }^{\mathrm{b}}$ Netherlands Vaccine Institute (NVI), P.O. Box 457, 3720 AL Bilthoven, The Netherlands \\ ${ }^{\mathrm{c}}$ Netherlands Centre Alternatives to Animal Use (NCA), Utrecht University, Yalelaan 17, 3584 CL Utrecht, The Netherlands
}

Received 9 May 2005; received in revised form 16 January 2006; accepted 24 January 2006

Available online 13 February 2006

\begin{abstract}
Many vaccines employed in childhood vaccination programmes are produced by conventional techniques, resulting in complex biological mixtures for which batch-related quality control requires in vivo potency testing. Monitoring consistency via in vitro tests during the vaccine production has the capacity to replace certain of the in vivo methods. In this respect, determining vaccine antigen immunogenicity through functional immunological tests has high potential. Advances in immunology have made it possible to analyse this biological activity by in vitro means. The present study established such an in vitro test system for tetanus toxoid (TT). This measured vaccine immunogenicity through an antigen-specific secondary (recall) response in vitro, using a porcine model growing in value for its closeness to human immune response characteristics. Discrimination between the specific recall TT antigen and diphtheria toxoid (DT) was possible using both peripheral blood mononuclear cell cultures and monocyte-derived dendritic cells in co-culture with autologous specific lymphocytes. TT-specific activation was detected with highest discrimination capacity using proliferation assays, as well as IFN-gamma and TT-specific antibody ELISPOTS (measuring secreting $\mathrm{T}$ and B lymphocytes, respectively). These in vitro systems show a high potential for replacing animal experimentation to evaluate the immunogenicity of complex vaccines.
\end{abstract}

(C) 2006 Elsevier Ltd. All rights reserved.

Keywords: In vitro antigen presentation; Tetanus toxoid; Vaccine quality control

\section{Introduction}

Vaccines, such as tetanus and diphtheria vaccines, which are to be employed in childhood vaccination programmes, are produced by the conventional techniques employing bacterial cell lysates containing tetanus toxin. The derived antigen is detoxified using formaldehyde, to form the basis for the tetanus vaccines. As a result, these vaccines are complex biological mixtures, and batch-related quality control testing in vivo is required to guarantee safety and potency.

\footnotetext{
* Corresponding author. Tel.: +31 30 2744595; fax: +31 302744408 .

E-mail address: Marlies.Leenaars@NVI-vaccin.nl (P.P.A.M. Leenaars).
}

According to the European Pharmacopoeia monograph, potency of tetanus vaccines can be determined using serological assays like, toxin-binding inhibition (ToBI) and ELISA and using challenge tests [1]. The state-of-the-art in quality control of new generation (well defined) vaccines is the consistency approach [2], aiming to monitor manufacturing processes towards assuring the quality of the final product. Good Manufacturing Practice - resulting in a more consistent product - and the availability of new immunochemical, physicochemical and biochemical techniques bring the consistency concept within reach of conventionally produced bacterial vaccines [3,4]. Minute changes in antigen structure can be missed by chemical analysis, but if these are important to the processing and presentation of the antigen, they will be detectable in terms of the immune response against 
the antigen [5]. Therefore, functional immunological tests are essential support for chemical analyses, to confirm the biological activity of the vaccine (antigen).

For an antigen to trigger specific immune responses, the critical cell involved is the dendritic cell (DC) [6]. These cells take up and process the antigen, presenting it in the context of peptide associated with major histocompatibility complex (MHC) molecules to T lymphocytes. Activated CD4 ${ }^{+} \mathrm{T}$-cells are required to help antigen-stimulated B lymphocytes to differentiate into antibody-secreting cells. The B-cells respond to the native antigen, and do not require processing by DCs, although the DCs can "deliver" the antigen to the B-cells and assist in B-cell differentiation [6]. In the case of tetanus, neutralising antibodies are essential for protection. Examining these processes in vitro for the consistency of vaccine production can provide important insight into the quality of the product, because modifications in the structure of an antigen can have a direct effect on how the DCs interact and process the material [7].

For the present study, an in vitro immune response model was developed to determine tetanus (vaccine) specific immunogenicity. A porcine model for a recall (secondary) immune response was established, due to the particularly close immunological relationship of pigs to humans (this is not the case between mice and humans). Cocultures of lymphocytes and DCs were analysed in terms of the specific immune response inducible, and the characteristics of that response with respect to lymphoproliferation, the CD25 lymphocyte activation marker, and the number of cells secreting IFN-gamma or tetanus-specific antibodies.

\section{Materials and methods}

\subsection{Isolation of peripheral blood mononuclear cells}

Swiss White Landrace pigs were housed under specific pathogen free (SPF) conditions. The animals were vaccinated and boosted with two human doses of tetanus vaccine (NVI, The Netherlands). Per experiment $400-600 \mathrm{ml}$ of venous blood was collected. Peripheral blood mononuclear cells (PBMCs) were isolated from the buffy coat fraction of blood by using density centrifugation at $1000 \times g$ for $25 \mathrm{~min}$ over Ficoll-Paque (Pharmacia, Sweden) [8].

\subsection{Proliferation assay using ${ }^{3} \mathrm{H}$-thymidine incorporation}

A dilution series in medium of tetanus toxoid (TT) or diphtheria toxoid (DT) (NVI, The Netherlands) was made in 96-well plates. Freshly isolated PBMCs were cultured in complete medium: Dulbecco's modified Eagle's medium (DMEM; Gibco, USA) containing 10\% (v/v) porcine serum (PS; Sigma-Aldrich, USA) with different concentrations of antigen at $39^{\circ} \mathrm{C}$, in $6 \%(\mathrm{v} / \mathrm{v}) \mathrm{CO}_{2}$. On days $3-5,{ }^{3} \mathrm{H}-$ thymidine (Hartman Analytica, Germany) was added, and the cultures incubated overnight under the same conditions. The next day, the plates were harvested on filtermats (Wallac, Finland) and analysed on a Microbeta counter (Wallac).

\subsection{Fluorescent labelling}

Murine monoclonal antibodies against CD3 (3E8), CD4 (PT90A) and CD8 $\alpha$ (PT81A) were purchased from VRMD, USA; anti-CD3 (PPT3) and anti-CD25 (231.3B2) were kindly provided by Dr. K. Haverson, University of Bristol, UK; anti-CD4 (74-12-4), anti-CD8 $\alpha$ (76-2-11) and antiSWC3 (CD172) (74-22-15) were kindly provided by Dr. A. Saalmüller, BFAV, Tübingen, Germany; anti-BrdU antibody was purchased from Beckton Dickinson, USA. Reaction of these antibodies was determined with appropriate antimouse isotype antibodies conjugated with FITC, PE or biotin (Southern Biotech, USA). As isotype-specific controls the conjugated antibodies were used leaving out the first antibody. The biotin-conjugated antibodies were revealed by a streptavidin-RPE-Cy5 conjugate (Dako, Denmark). In general, antibodies were incubated with the cells for $30 \mathrm{~min}$ on ice, the samples were washed with Cellwash (Becton Dickinson), and the cells were spun at $400 \times g$ for $5 \mathrm{~min}$. The samples were analysed on a FACSCalibur (Becton Dickinson) using the CellQuest pro software (Becton Dickinson) [9].

\subsection{BrdU incorporation assay}

Freshly isolated PBMCs were cultured as described above in the presence of $200 \mathrm{uM} \mathrm{BrdU}$ (Sigma-Aldrich) and $10 \mu \mathrm{g} / \mathrm{ml}$ phytohaemagglutinin (PHA; Sigma-Aldrich), 1.2 limit of flocculation units (Lf) per millilitre TT or DT antigen. After 3 or 6 days of incubation, the cells were harvested. The cell surface markers were labelled as above, then intracellular BrdU was detected. For the latter, the cells were fixed and permeabilised in two steps using $95 \%(\mathrm{v} / \mathrm{v})$ ethanol (fixation) followed by $0.1 \%(\mathrm{w} / \mathrm{v})$ paraformaldehyde plus $0.01 \%$ (v/v) Tween 20 in phosphate buffered saline (PBS) (permeabilisation). DNA was degraded with $500 \mathrm{U} / \mathrm{ml}$ Dnase I (Amersham Biosciences, Sweden). After fixation, permeabilisation and DNA degradation, intracellular BrdU was detected as described elsewhere $[10,11]$.

\subsection{IFN-gamma ELISPOT}

Mouse anti-pig IFN-gamma $(5 \mu \mathrm{g} / \mathrm{ml}$, PIERCE endogen, USA) monoclonal antibody (mAb) was added to multiscreen plates (Millipore, USA) and incubated overnight at $4{ }^{\circ} \mathrm{C}$. The next day, the plates were blocked with complete medium. A two-fold dilution series of PBMCs were made, various concentrations of antigen were added, and the plates incubated for 2 or 5 days at $37^{\circ} \mathrm{C}$. The wells 
were then washed with PBS and $1 \mathrm{mg} / \mathrm{ml}$ rabbit anti-porcine IFN-gamma polyclonal antibody (PIERCE endogen) was added. After $1 \mathrm{~h}$ incubation at room temperature, the wells were washed with PBS. Swine anti-rabbit peroxidase conjugate diluted 1:100 (Dako, Switzerland) was added. Staining was performed using fast 3,3'-diaminobenzidine tablet sets (Sigma-Aldrich). The plates were dried and analysed in an ELISPOT-reader (AID, Germany).

\subsection{Antibody ELISPOT}

PBMCs were cultured in DMEM containing $10 \%(\mathrm{v} / \mathrm{v})$ foetal calf serum (FCS; Biochrome, Germany) in the presence of $100 \mathrm{U} / \mathrm{ml} \mathrm{IL-2} \mathrm{(kindly} \mathrm{provided} \mathrm{by} \mathrm{Dr.} \mathrm{S.} \mathrm{Inumaru,}$ Institute for Animal Health, Ibaraki, Japan) and $50 \mu \mathrm{M} \beta$ mercaptoethanol (Invitrogen, Switzerland). The cells were cultured for 5 days in the presence of antigen or mitogen. One day before harvesting the cells, multiscreen plates were coated with $10 \mathrm{Lf} / \mathrm{ml}$ TT antigen in PBS, and incubated overnight at $4{ }^{\circ} \mathrm{C}$. The plates were blocked with DMEM containing $10 \%(\mathrm{v} / \mathrm{v}) \mathrm{FCS}$ at $37^{\circ} \mathrm{C}$ for $2 \mathrm{~h}$. PBMCs were harvested for plating in DMEM containing $10 \%(\mathrm{v} / \mathrm{v})$ FCS on to the multiscreen plates, and then incubated overnight at $37^{\circ} \mathrm{C}$ in $6 \%(\mathrm{v} / \mathrm{v}) \mathrm{CO}_{2}$. A goat-anti-pig IgG HRP-conjugated antibody (1:5000, Bethyl Laboratories, USA) was added and incubated for $3 \mathrm{~h}$ at $37^{\circ} \mathrm{C}$. Reaction of the conjugate was revealed using fast 3,3'-diaminobenzidine tablet sets (Sigma-Aldrich). The plates were dried and analysed in an ELISPOT-reader.

\subsection{Monocyte-derived DC based antigen presentation assays}

Anti-CD172a was used to purify monocytes from PBMCs using magnetic activated cell sorting (MACS, Miltenyi Biotech, Germany) [12]. Monocytes were induced to differentiate into monocyte-derived DCs (MoDCs) has previously been described [13]. Briefly, monocytes were cultured at $1 \times 10^{6}$ cells $/ \mathrm{ml}$ in DMEM plus $10 \%(\mathrm{v} / \mathrm{v})$ FCS containing IL-4 (100 U/ml prepared as described by Carrasco et al. [12]) and GM-CSF ( $150 \mathrm{ng} / \mathrm{ml}$; kindly provided by Dr. S. Inumaru) for 3 days. The CD172a ${ }^{-}$cells were used as source of lymphocytes which were co-cultured with the MoDCs at different DC:lymphocyte ratios, together with TT or DT antigen at $1.2 \mathrm{Lf} / \mathrm{ml}$ for 4 days at $39{ }^{\circ} \mathrm{C}$ in $6 \%(\mathrm{v} / \mathrm{v}) \mathrm{CO}_{2}$. On day $3,{ }^{3} \mathrm{H}-$ thymidine was added, and the cultures incubated overnight. The plates were then harvested and analysed on a Microbeta counter.

\section{Results}

\subsection{TT antigen-induced proliferation of T-cells in vitro}

The specificity of TT antigen presentation in vitro was determined using PBMCs isolated from pigs vaccinated with

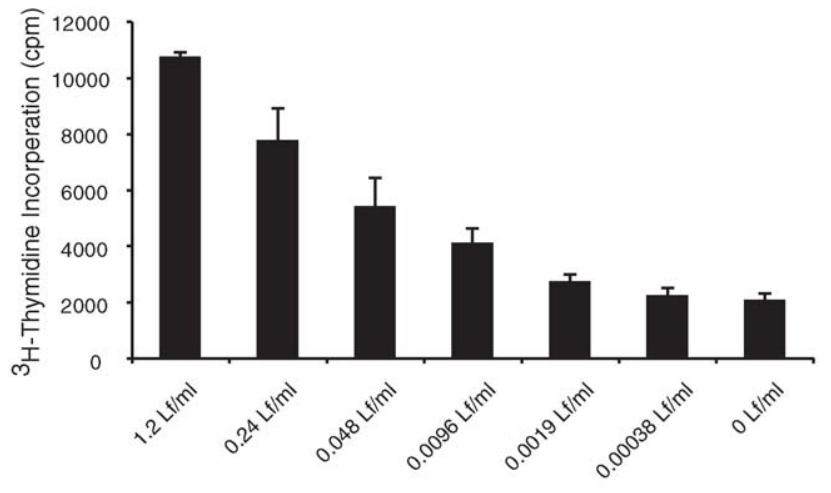

(a)

tetanus toxoid

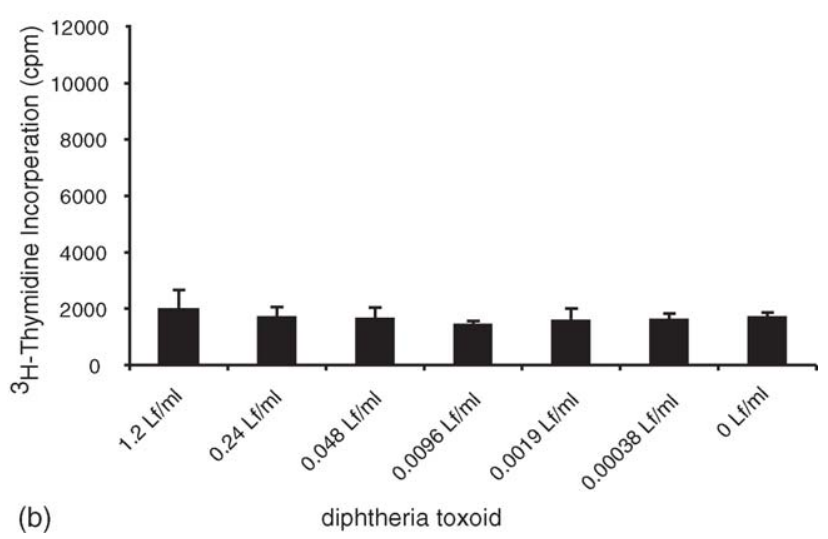

Fig. 1. Lymphoproliferative response of PBMC from a TT-vaccinated pig, measured by ${ }^{3} \mathrm{H}$-thymidine incorporation at 6 days post-stimulation in vitro with varying concentrations ( $x$-axis) of: (a) TT antigen (positive stimulation) or (b) DT antigen (negative control).

the TT vaccine, cultured with the antigen $(1.2 \mathrm{Lf} / \mathrm{ml})$. DT antigen - the inactivated form of a three-subunit diphtheria toxin, similar to TT - was used as negative control. A TT antigen-specific induction of PBMC proliferation was noted in a dose-dependent manner (Fig. 1).

\subsection{Identification of activated T-cells by BrdU incorporation in vitro}

PBMCs from a vaccinated animal were cultured for 3 or 6 days in the presence of TT antigen and BrdU. Again DT antigen was used as a negative control, and PHA as a positive control for polyclonal T-cell activation. Following the incubation with the antigen, non-adherent cells were harvested, and the level of incorporated BrdU determined. The BrdU ${ }^{+}$ cells were characterised in terms of their expression of the $\mathrm{T}$ lymphocyte markers CD3, CD4 and CD8. Compared to the unstimulated control (Fig. 2a), PBMCs stimulated with the polyclonal T-cell mitogen PHA-induced BrdU-incorporation into a large proportion of the T-cells after 6 days, particularly the $\mathrm{CD}^{+}{ }^{+}$cells (Fig. 2b). In contrast, the percentage of cells showing BrdU incorporation following TT antigen stimulation was low (Fig. 2c) and not different from 

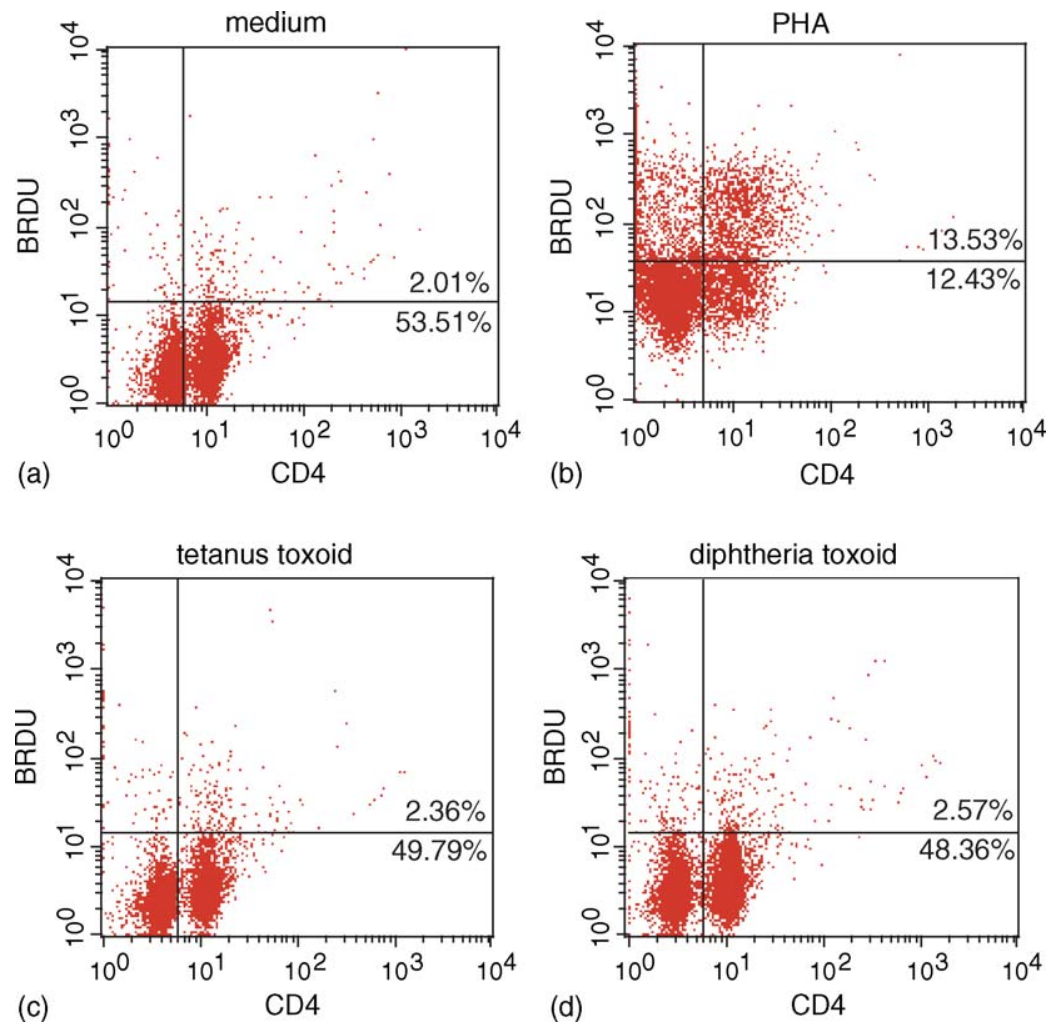

Fig. 2. Analysis of the lymphoproliferative response of PBMC from TT-vaccinated pigs, measured at 6 days post-stimulation in vitro with: (a) medium alone, (b) PHA, (c) $1.2 \mathrm{Lf} / \mathrm{ml}$ TT antigen and (d) $1.2 \mathrm{Lf} / \mathrm{ml}$ DT antigen. Incorporation of BrdU by PBMCs was measured, following gating on the CD3 ${ }^{+}$ T-cells.

the DT antigen stimulated cultures (Fig. 2d). Consequently, this method of measurement was dropped due to its lack of sensitivity.

\subsection{Detection of $T$-cell activation in terms of CD25 expression}

PBMCs from a TT antigen-vaccinated animal were cultured in the presence of TT antigen, or DT antigen as negative control and Con A as positive control, for 3 or 6 days. The cells were then harvested, and labelled for expression of CD3, CD4, CD8 and CD25. The different subpopulations of T-cells were identified by flow cytometry and gated as shown in Fig. 3a. From this, the percentage of CD25 cells was calculated (Fig. 3b). As expected, the polyclonal mitogen Con A induced CD25 expression on all $\mathrm{T}$ lymphocytes including $\mathrm{CD}^{-} \mathrm{CD}^{+}$cytotoxic $\mathrm{T}$ lymphocytes $\left(\mathrm{T}_{\mathrm{c}}\right)$, the $\mathrm{CD}^{+}{ }^{+} \mathrm{CD} 8^{+}$memory/activated $\mathrm{T}$ helper lymphocytes $\left(\mathrm{T}_{\mathrm{h}}\right)$ and the $\mathrm{CD} 4^{+} \mathrm{CD} 8^{-}$naïve $\mathrm{T}_{\mathrm{h}}$ lymphocytes. TT antigen-stimulation of $\mathrm{CD} 25$ expression was primarily noted within the $\mathrm{CD} 4^{+} \mathrm{CD} 8^{+}$memory/activated $\mathrm{T}_{\mathrm{h}}$ cell subpopulation after 6 days of stimulation. No significant differences were detected in the percentage of subpopulations T-cells between different stimuli (data not shown). The DT antigen (negative control) induced no upregulation with any of the T-cell populations.

\subsection{Immune activation in vitro measured by IFN-gamma ELISPOT}

Due to the fact that activated $\mathrm{CD} 4^{+} \mathrm{T}_{\mathrm{h}}$ cells produce the cytokines required for differentiation of B-cells and other T-cells [7], the ability of the TT antigen to induce IFNgamma secretion in vitro was studied using an ELISPOT assay [14]. TT antigen stimulation of PBMCs isolated from the vaccinated animals was compared with DT stimulation as a negative control in a dose-dependent manner starting at $1.2 \mathrm{Lf} / \mathrm{ml}$. Concentrations of the TT antigen down to $0.0096 \mathrm{Lf} / \mathrm{ml}$ induced clearly detectable IFN-gamma spots in the assay, and the number of spots visualised was dependent on the dose of antigen (Fig. 4a). In contrast, no IFN-gamma spots were visible when the DT antigen was used as the stimulant (Fig. 4b), whereas the Con A positive control induced high numbers of IFN-gamma secreting cells. Clearly, the ELISPOT assay is a sensitive method to measure specific TT responses in vitro.

\subsection{Immune activation in vitro measured by antibody ELISPOT}

The critical element of the protective immune response against tetanus is TT-specific serum antibodies. It is therefore essential that any in vitro assay of TT vaccine 

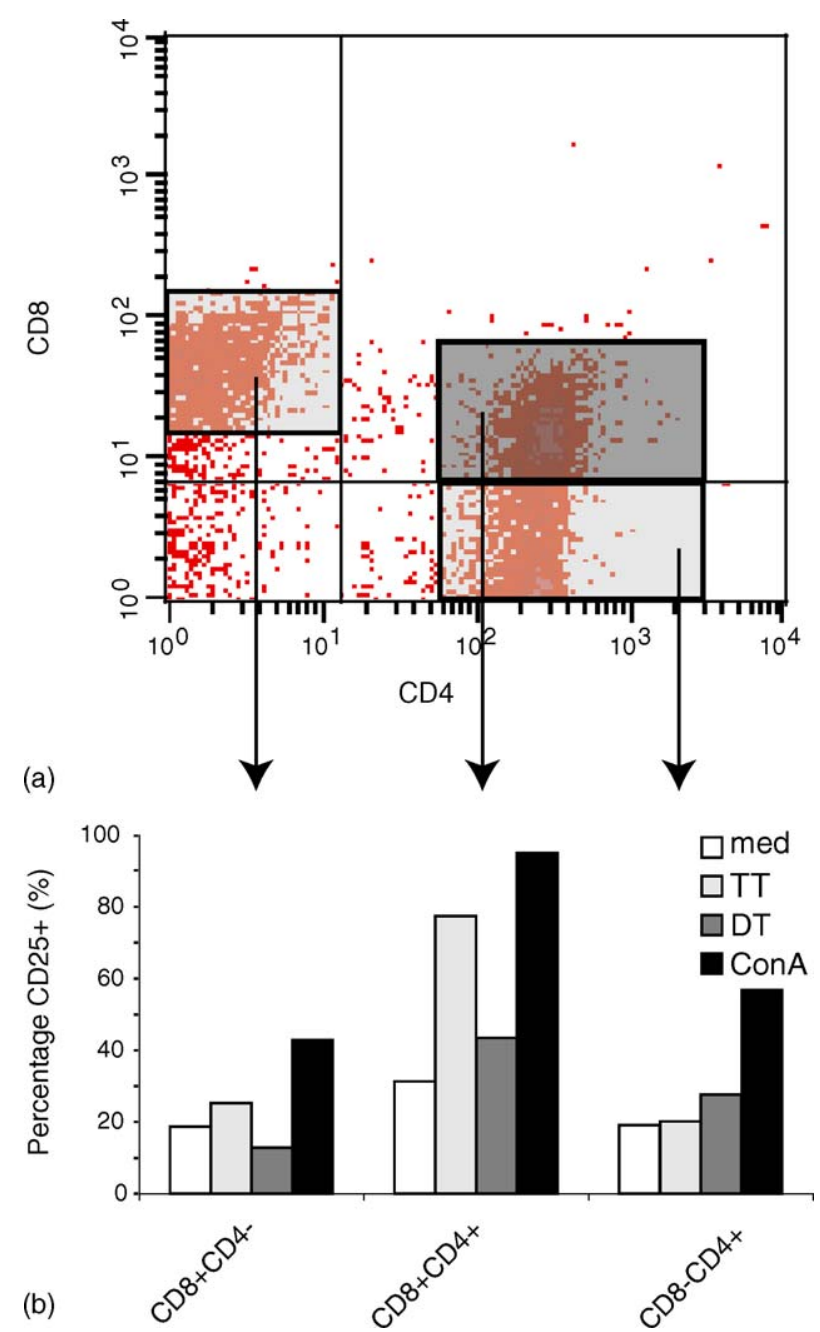

Fig. 3. Identification of CD25 upregulation on PBMCs at 6 days poststimulation in vitro with TT, DT, Con A or medium (no antigen). (a) CD3+ lymphocytes after TT stimulation. The different T-cell subpopulations were identified in terms of CD4/CD8 expression: $\mathrm{CD}^{-}{ }^{-} \mathrm{CD} 8^{+} \mathrm{T}_{\mathrm{c}}$ cells, $\mathrm{CD} 4^{+} \mathrm{CD} 8^{+}$activated/memory $\mathrm{T}_{\mathrm{h}}$ cells and $\mathrm{CD} 4^{+} \mathrm{CD} 8^{-}$naïve $\mathrm{T}_{\mathrm{h}}$ cells. (b) Ratios of $\mathrm{CD} 25^{+}: \mathrm{CD} 25^{-}$populations $\left(\% \mathrm{CD} 25^{+}\right)$were calculated for each of the T-cell subpopulations shown in (a).

immunogenicity measure the capacity of the vaccine to induce specific antibodies. Due to the sensitivity of the ELISPOT assay for quantifying the number of producing cells, this was applied to the measurement of antiTT antibody production [15]. High levels of TT-specific antibody-secreting B-cells were visualised following the in vitro stimulation of PBMCs with TT antigen (Fig. 5). These cultures usually contain around 10-20\% B-cells (data not shown). Based on this the frequency of TT-specific B-cells was $2-5 \%$ of total B-cells. The DT antigen did not induce B-cells to secrete TT-specific antibodies. There was no detectable background level of antibody production by this assay (medium control), which makes this assay both sensitive and specific for the detection of anti-TT antibody.
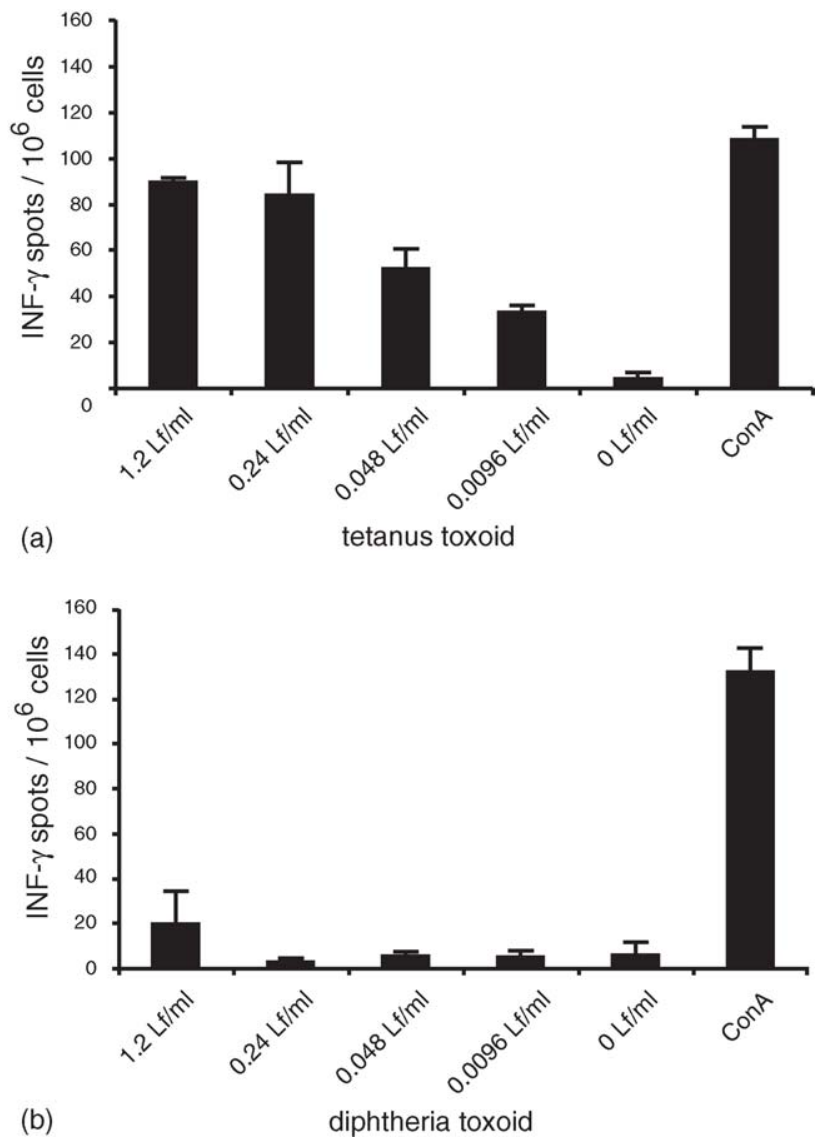

Fig. 4. IFN-gamma ELISPOT was applied to analysis of the PBMCs from TT-vaccinated pigs at 2 days post-stimulation in vitro with varying concentrations ( $x$-axis) of: (a) TT antigen or (b) DT antigen. The number of cells per $10^{6}$ secreting IFN-gamma ( $y$-axis) is shown.

\subsection{MoDCs in co-culture with antigen-specific lymphocytes to identify TT-specific immune responses in vitro}

In order to determine the capacity of DCs to induce TTspecific T-cell proliferation in vitro, MoDCs were first generated using GM-CSF and IL-4. The non-adherent MoDCs

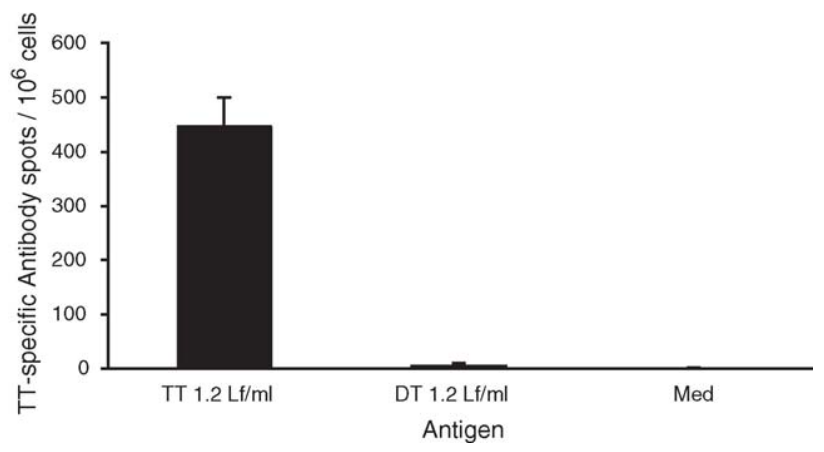

Fig. 5. Antibody-secreting B-cell ELISPOT applied to the analysis of PBMCs from TT-vaccinated pigs at 5 days post-stimulation in vitro with $1.2 \mathrm{Lf} / \mathrm{ml}$ of either TT antigen, DT antigen or no antigen (med). The number of cells per $10^{6}$ secreting anti-TT-specific antibody ( $y$-axis) is shown. 


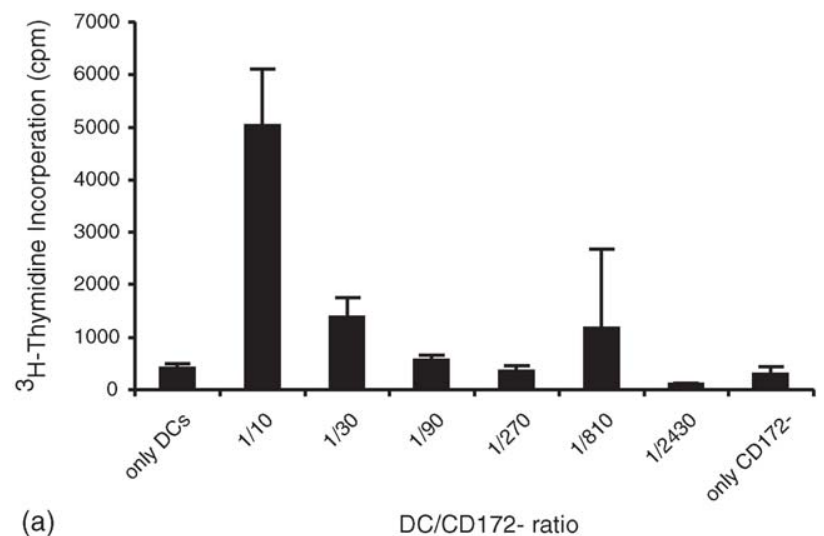

(a)

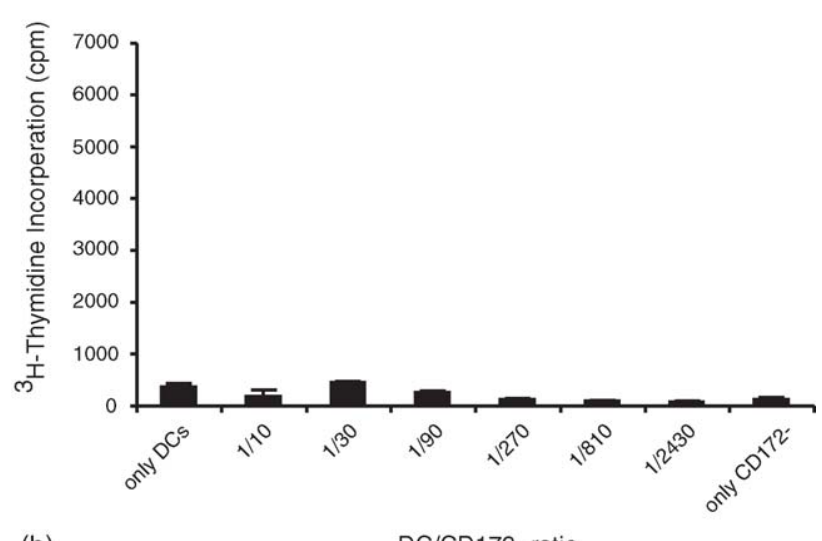

(b)

DC/CD172- ratio

Fig. 6. (a) TT- and (b) DT-induced proliferation after co-culture of MoDCs with lymphocytes ( $>95 \%$ purity) at varying DC:CD172- cells ratios ( $x$-axis).

were harvested and co-cultured with CD172 depleted autologous lymphocytes from a TT-vaccinated animal, together with TT or DT antigen. At a DC:CD172 ${ }^{-}$cell ratio of $1: 10$, the MoDCs presented antigen to stimulate the responder cells in a TT-specific proliferation (Fig. 6a). Again, this response was not observed with the DT negative control antigen (Fig. 6b).

\section{Discussion}

For in vitro immunological procedures to have applicability for vaccine testing, and be of value in replacement of animal experimentation, it is necessary that they identify vaccine immunogenicity. To this end, a TT-specific response was employed with in vitro cultures of freshly isolated leukocyte subpopulations from porcine peripheral blood. The cells utilised for the assay were derived from a previously vaccinated animal-the aim was to determine the applicability of the assay for testing vaccines in a consistent manner, rather than attempting to analyse the in vivo response following vaccination. The latter is rather difficult to design in terms of an in vitro test, due to the difficulty to induce primary immune response in vitro. For this reason, cells from an vaccinated animal were employed, providing a model for recall responses, which is more sensitive and more applicable than primary responses for determining vaccine immunogenicity consistency in vitro. Such secondary immune response models are applicable to screening large numbers of samples in a comparative manner, promoting an analysis of vaccine consistency.

Both PBMCs freshly isolated from the blood, and DClymphocyte co-cultures were employed, the cells coming from a TT-vaccinated animal. DCs are the major population involved in antigen presentation to T-cells during primary and secondary responses [6]. B-cells can function in antigen presentation to T-cells, but in the secondary response, although this is less efficient compared with the capacity of the DCs [16]. Removal of DCs from in vitro restimulation cultures obviates the responsiveness of all lymphocytes to TT antigen and FMDV antigen, even in a secondary in vitro response model (Barnard, Piersma, Bergamin, Summerfield and McCullough, unpublished data). For the in vitro test system being developed, the specificity of the induced response was assessed with TT-recall antigen and DT antigen as a negative control. A specific response was clearly detectable using a ${ }^{3} \mathrm{H}$-thymidine-based lymphoproliferation test. This was seen with both the PBMC cultures and the DC-lymphocyte co-cultures. Nevertheless, the MoDC based co-cultures did not offer an advantage over the use of PBMCs - the latter already contain potent DC subsets able to present antigen to T-cells [17]. One advantage for the MoDC cultures may be with the application of DC lines, but this would have to be investigated, and suffers from the problems of a small range of MHC haplotypes available. Using primary DC cultures offers the possibility of selecting donors with the MHC haplotypes required.

Measurement of vaccine immunogenicity in vitro was further analysed by applying the BrdU incorporation assay and detection of CD25 expression. The BrdU-based method lacked sensitivity in detecting a TT-specific response, although it was capable of detecting a polyclonal $\mathrm{T}$ lymphocyte response induced by a T-cell mitogen. With lower numbers of TT-specific lymphocytes being responsive to the antigen compared with the numbers responding to the mitogen, this test was inadequate to detect specific anti-TT proliferation. In contrast, flow cytometric analysis of the CD25 lymphocyte-activation marker clearly detected a TT-specific response. This was notable in both the $T_{c}$ and $T_{h}$ lymphocyte subpopulations, dominating in the activated/memory $\mathrm{CD}^{+} \mathrm{CD}^{+} \mathrm{T}_{\mathrm{h}}$ cell subset identifiable in the pig [18]. Not all of these $\mathrm{CD} 4^{+} \mathrm{CD} 8^{+} \mathrm{CD} 25^{+}$cells would be memory $\mathrm{T}_{\mathrm{h}}$ lymphocytes, because activated naïve porcine $\mathrm{T}_{\mathrm{h}}$ lymphocytes can also upregulate CD8 expression (Summerfield and Saalmüller, unpublished observations). There was indeed an increase in the numbers of $\mathrm{CD} 4^{+} \mathrm{CD} 8^{+} \mathrm{CD} 25^{+}$cells in response to the DT antigen, albeit much lower than with the TT antigen, which would signify a level of primary immune response by naïve cells.

Activation of the lymphocytes was confirmed by incorporating functional analyses into the assay model. Secretion 
of IFN-gamma - a cytokine produced in high quantities during cellular immune responses [7] - was identified by ELISPOT assay. This is a sensitive measurement for TTspecific responses, detecting a quantitative response by measuring the number of producing cells. The DT antigen also induced some IFN-gamma secreting cells, relating to the CD25 measurements suggesting a primary response. Again this was much lower than the TT antigen induced levels, and only the highest dose of DT antigen was effective, whereas TT antigen induced in a dose-dependent manner. This demonstrates another characteristic of the primary versus secondary immune response.

B lymphocyte functionality was also measurable, in terms of specific antibody production. Again the number of producing cells were analysed (by ELISPOT) to provide more quantitative information, proving to be a particularly sensitive and reliable measurements of TT-specific responses. Immune responsiveness measured in terms of the number of B-cells producing antibody is a pertinent indicator for vaccine immunogenicity. When vaccines are being tested at different points during their manufacture, or different batches of vaccine are being compared, this test will give a consistent monitor of vaccine quality. Differences in the number of B-cells responding will reflect vaccine efficiency at interacting with both the B-cells and the T lymphocytes essential for B lymphocyte differentiation. Moreover, with B-cells recognising native unprocessed antigen, this readout can provide additional information on antigen quality. In addition, antibody is the critical factor in the development of an efficacious immune defence against tetanus, requiring that vaccines be most immunogenic in terms of inducing B-cell productivity.

The above discussion has focussed on the applicability of the in vitro assays to testing TT vaccines, but the model would also be appropriate for testing TT as a carrier protein. T-cell stimulatory capacity of TT carriers has been used successfully to enhance the immunogenicity of antigens such as Haemophilus influenzae type b capsule, and group $\mathrm{A}$ and $\mathrm{C}$ meningococcus [19-21]. Manufacturing conjugate vaccines is expensive and labour intensive, and in process quality monitoring of these may require non-immunogenic carriers to be cost effective. In vitro immune response models would be useful for quality control of such protein carriers in conjugate vaccines.

The present study established a TT-specific in vitro response model for determining antigen immunogenicity. Especially proliferation and antibody and IFN-gamma ELISPOT show high TT-specific responses indicating that these tests are representing a promising tool for vaccine quality control purposes. Current efforts are looking at the applicability of in vitro assay models using human PBMCs (Piersma, Leenaars, Hendriksen, van Els and Rijkers, unpublished data), to determine correlates of vaccine efficacy and applicability for screening large numbers of vaccine candidates or in-process test materials. It is suggested that in the near future replacement of certain in vivo potency testing should be possible with the appropriate set of chemical tests together with in vitro immune response models.

\section{Acknowledgements}

The authors wish to thank Valérie Tâche for assistance with the lymphocyte and MoDC cultures, Heidi Gerber for preparation of the Mabs, and Daniel Brechbühl for vaccination and bleeding of the animals. This project was supported by the Netherlands Organisation for Health Research and Development (ZonMw; Project 3170.0060).

\section{References}

[1] European Pharmacopoeia. Assay of tetanus vaccine (adsorbed). In: European Pharmacopoeia, vol. 5.0; 2005. p. 198-202.

[2] Castle P. Combined vaccines: policy and practice in the European Pharmacopoeia. Biologicals 1994;22(4):381-7.

[3] Leenaars PPAM, Kersten GFA, de Bruijn MLH, Hendriksen CFM. An in vitro approach in quality control of toxoid vaccines. Vaccine 2001;19:2729-33.

[4] Metz B, Jiskoot W, Hennink WE, Crommelin DJA, Kersten GFA. Physicochemical and immunochemical techniques predict the quality of diphtheria toxoid vaccines. Vaccine 2003;22(2):156-67.

[5] Antoniou AN, Blackwood SL, Mazzeo D, Watts C. Control of antigen presentation by a single protease cleavage site. Immunity 2000;12(4):391-8.

[6] Banchereau J, Steinman RM. Dendritic cells and the control of immunity. Nature 1998;392(6673):245-52.

[7] Kapsenberg ML. Dendritic-cell control of pathogen-driven T-cell polarization. Nat Rev Immunol 2003;3(12):984-93.

[8] McCullough KC, Schaffner R, Fraefel W, Kihm U, Summerfield A. The relative density of CD44-positive porcine monocytic cell populations varies between isolations and upon culture and influences susceptibility to infection by African swine fever virus. Immunol Lett 1993;37(1):83-90.

[9] Summerfield A, McCullough KC. Porcine bone marrow myeloid cells: phenotype and adhesion molecule expression. J Leukoc Biol 1997;62(2):176-85

[10] Piriou L, Chevallier S, Hutet E, Charley B, Le Potier MF, Albina E. Humoral and cell-mediated immune responses of $\mathrm{d} / \mathrm{d}$ histocompatible pigs against classical swine fever (CSF) virus. Vet Res 2003;34(4):389-404.

[11] Adriaansen HJ, Osman C, van Dongen JJ, Wijdenes-de Bresser JH, Kappetijn-van Tilborg CM, Hooijkaas H. Immunological marker analysis of mitogen-induced proliferating lymphocytes using BrdU incorporation or screening of metaphases Staphylococcal protein $\mathrm{A}$ is a potent mitogen for CD4+ lymphocytes. Scand J Immunol 1990;32(6):687-94

[12] Carrasco CP, Rigden RC, Schaffner R, Gerber H, Neuhaus V, Inumaru $\mathrm{S}$, et al. Porcine dendritic cells generated in vitro: morphological, phenotypic and functional properties. Immunology 2001;104(2):175-84.

[13] Carrasco CP, Rigden RC, Vincent IE, Balmelli C, Ceppi M, Bauhofer $\mathrm{O}$, et al. Interaction of classical swine fever virus with dendritic cells. J Gen Virol 2004;85(Pt 6):1633-41.

[14] Schmittel A, Keilholz U, Bauer S, Kuhne U, Stevanovic S, Thiel E, et al. Application of the IFN-gamma ELISPOT assay to quantify $\mathrm{T}$ cell responses against proteins. J Immunol Methods 2001;247(1-2):17-24.

[15] Nanan R, Heinrich D, Frosch M, Kreth HW. Acute and long-term effects of booster immunisation on frequencies of antigen-specific memory B-lymphocytes. Vaccine 2001;20(3-4):498-504. 
[16] Watts C, Lanzavecchia A. Suppressive effect of antibody on processing of $\mathrm{T}$ cell epitopes. J Exp Med 1993;178(4):145963.

[17] Summerfield A, Guzylack-Piriou L, Schaub A, Carrasco CP, Tache $\mathrm{V}$, Charley B, et al. Porcine peripheral blood dendritic cells and natural interferon-producing cells. Immunology 2003;110(4): $440-9$.

[18] Summerfield A, Rziha HJ, Saalmuller A. Functional characterization of porcine CD4+CD8+ extrathymic T lymphocytes. Cell Immunol 1996;168(2):291-6.
[19] Anderson P, Pichichero ME, Insel RA. Immunogens consisting of oligosaccharides from the capsule of Haemophilus influenzae type $\mathrm{b}$ coupled to diphtheria toxoid or the toxin protein CRM197. J Clin Invest 1985;76(1):52-9.

[20] Jennings HJ, Lugowski C. Immunochemistry of groups A, B, and C meningococcal polysaccharide-tetanus toxoid conjugates. J Immunol 1981;127(3):1011-8.

[21] Schneerson R, Barrera O, Sutton A, Robbins JB. Preparation, characterization, and immunogenicity of Haemophilus influenzae type $\mathrm{b}$ polysaccharide-protein conjugates. J Exp Med 1980;152(2):361-76. 